stars, and has communicated fifteen papers on that subject to the Society. Mr. Hargreaves has rendered important services to astronomy by the design of valuable instrumental accessories. He has devised an electric drive for telescopes which has been very successfully applied to the 28 -inch equatorial at Greenwich. He also constructed a "comparison image micrometer" with which he made double-star observations with an accuracy which compared very favourably with that of observations made with the filar micrometer. In addition, he has produced mirrors and other work of high excellence. His contributions to astronomical observation have been chiefly in the delineation of planetary detail, but he has given much attention to astronomical photography.

\section{Geological Society of London Awards}

THE council of the Geological Society has made the following awards: Wollaston Medal to Prof. Maurice Lugeon, of the University of Lausanne, in recognition of the value of his researches on the mineral structure of the earth, particularly in respect of the geological structure of the Alps and of mountain building ; Murchison Medal to Dr. Henry Howe Bemrose, in recognition of his researches upon the igneous rocks of the Lower Carboniferous of Derbyshire, and also upon the Pleistocene fauna of the same area ; Lyell Medal to Dr. John Pringle for his services to palæontological science, and particularly in recognition of his work in connexion with the Geological Survey and Museum; Wollaston Fund to Dr. Henry Francis Harwood, of the Imperial College of Science and Technology, in recognition of his research work on the chemistry of minerals and rocks ; Murchison Fund to Dr. Frank Coles Phillips, for his contributions to metamorphism and structural petrology; a moiety of the Lyell Fund to Dr. Sydney Ewart Hollingworth, for his work on the Lower Carboniferous rocks, and the structural geology of the Lake District and northern Pennines, and on the Vale of Eden glaciation; another moiety of the Lyell Fund to Dr. Frederick Murray Trotter, for his geological researches, especially on the glacial and post-glacial phenomena of the Eden Valley.

\section{$\varepsilon$ Aurigæ-a Super-giant Star}

UNTI the requisite details are available in the Astrophysical Journal regarding Dr. O. Struve's discovery of the precise nature of the eclipsing binary system of $\varepsilon$ Aurigæ, no useful comments can here be made. It may be inferred, however, from the Press reports that a study by Dr. Struve of the infrared spectrum of the star obtained with sufficiently high dispersion has shown that the chief component of the system is a super-giant star with a radius some 3,000 times that of the sun. The star of largest radius hitherto known is Antares, the radius of which is about 450 times the sun's. $\varepsilon$ Aurigæ, the light variation of which is of Algol type but with an exceptionally long period of $27 \cdot 1$ years, has long been the subject of intensive observation, mainly in Germany, in the United States and in Canada. The spectroscopic history of the star up to 1928 is summarized in "Handbuch der Astrophysik", 6, Pt. 2, 466 (1928). Results obtained at the Yerkes Observatory by Frost, Struve and Elvey at the last light minimum in 1928-29 are given in the publications of that observatory in vol. 7, Pt. 2. During the same epoch, Adams and Sanford were able to distinguish clearly on their high-dispersion spectra taken at Mount Wilson a faint component on the redward side of the enhanced lines and those of hydrogen. They pointed out the necessity of obtaining high-dispersion spectrograms of $\varepsilon$ Aurigæ at other epochs of the period of light variation in order to trace the origin of the faint spectral component.

\section{Recent Advances in Glass Technology}

TWENTY-ONE years ago was a strenuous period for British technologists, and in no field were the problems more urgent than in connexion with the production of glass for laboratory, optical and many other purposes ; thus the necessity of team-work brought the Society of Glass Technology into existence, and its coming-of-age has recently been celebrated. A series of lectures on "Glass in Modern Life", arranged by the Society in this connexion, recalled some of the veritable struggles of the period of the Great War, and the more ordered progress of this 'key industry' under the subsequent measure of protection accorded to it. Prof. W. E. S. Turner mentioned that the value of the production of the chemical and scientific glassware industries has risen from $£ 129,000$ in 1924 to $£ 250,000$ in 1937 , and is doubtless even higher today. Undoubtedly, the activities of the Society have contributed in no small degree to the possibility of this expansion, and the same is true of Prof. Turner himself and the Glass Technology Department at the University of Sheffield. The term 'glass' covers a very wide variety of chemical substances; when we find it being employed in these days (inter alia) for nuts and bolts, woven fabrics (of course for highly specialized purposes), and bricks for building, we may wonder whether the golden age of glass production is only just beginning. The list of lecturers also included Mr. Raymond McGrath and Mr. Bernard P. Dudding, who dealt with the applications of glass in their special fields of architecture and illuminating engineering respectively; and Dr. W. M. Hampton contributed a lecture on new developments in the field of optical glass. Although the production of optical glass may be a very minor activity from the business point of view, the experience gained in efforts to improve it has been invaluable in its. lessons for the larger-scale operations.

\section{Cave Paintings and Military Operations in Spain}

WHILE anxiety was felt generally throughout the world as to the fate which was likely to befall the artistic treasures of Spain until reassurance was given by Sir Frederic Kenyon's visit of inspection to the scene of hostilities, archæologists were no less perturbed at the thought of the damage which might be done to the priceless palæolithic paintings of the caves of northern and eastern Spain, both within the 